\title{
MANO ELÓI E O SAMBA NA DINÂMICA DA CULTURA NEGRA BRASILEIRA UM SEMEADOR DE ESCOLAS DE SAMBA
}

Sormani da Silva (Cefet/RJ)

O objetivo deste artigo é analisar a diáspora do sambista Mano Elói, que migrou da região do Vale do Paraíba para a cidade do Rio de Janeiro no início do século XX. Destaco seu percurso, entre os subúrbios e a cidade, como um elemento fundamental para a configuração da malha de escolas de samba. Abordo também a experiência de Mano Elói ao levar para o disco os registros dos primeiros cânticos das religiões de matriz africana.

ESCOLA DE SAMBA; MANO ELÓI; CULTURA NEGRA.

SILVA, Sormani da. Mano Elói e o samba na dinâmica da cultura negra brasileira: um semeador de escolas de samba. Textos escolhidos de cultura e arte populares, Rio de Janeiro, v.12, n.2, p. 103115, nov. 2015. 


\section{MANO ELOI AND THE SAMBA IN THE DYNAMICS OF BRAZILIAN BLACK CULTURE}

A SAMBA-SCHOOLS SOWER

Sormani da Silva (Cefet/RJ)

The objective of this article is to analyse the diaspora of the samba composer Mano Elói, who migrated from Vale do Paraiba to Rio de Janeiro city in the beginning of the twentieth century. His trajectory will be reported in the suburbs and the city as a fundamental element to the configuration of the network of samba schools. It will also deal with Mano Elói's experience of recording the first religious songs of African origin.

SAMBA SCHOOL; MANO ELÓI; BLACK CULTURE.

SILVA, Sormani da. Mano Elói e o samba na dinâmica da cultura negra brasileira: um semeador de escolas de samba. Textos escolhidos de cultura e arte populares, Rio de Janeiro, v.12, n.2, p. 103115, nov. 2015. 
Durante todos esses anos, fosse como membro ou como presidente, nunca deixei de sambar, pois isso foi minha vida (MANO ELól, 20/2/1971, p. 2).

Nascido em Engenheiro Passos, no Vale do Paraíba, em 1889, Mano Elói chegou à cidade do Rio de Janeiro com 15 anos, fixando-se como vendedor de balas ao lado do seu tio, Zé das Colunas, nas imediações do Campo de Santana. Sua trajetória está ligada à profunda mudança social que aconteceu na sociedade brasileira no final do século XIX: a abolição da escravidão. Nesse contexto, um significativo fluxo de populações, historicamente vinculadas ao trabalho rural, migrou para os principais centros em busca de oportunidades de trabalho. A crise do sistema produtivo do velho Vale do Paraíba, interior do Estado do Rio, bem como de Minas Gerais, Bahia e Espírito Santo, potencializou o processo migratório que teve como destino cobiçado o então Distrito Federal. Uma pesquisa realizada pela Fundação Leão XIII, ${ }^{1}$ em 1950, para fins de orientar política pública, confirmou que diversas famílias da Favela da Barreira do Vasco vieram dessas regiões. No debate sobre o crescimento das favelas na cidade, muitos alertavam para a necessidade de políticas que garantissem vida digna para fixar essas populações em seus estados de origem. A migração para os principais centros, entretanto, se intensificou com o processo de desenvolvimento do país.

Assim, além do processo estrutural provocado pela falta de oportunidades nessas áreas rurais, havia uma questão de ordem psicossocial. Para muitos trabalhadores a questão de abandonar essas regiões significava promover o esquecimento das relações construídas ao longo do sistema escravista. Numa conversa com Rubens da Vila, ${ }^{2}$ natural de Campos, o compositor afirmou que também migrou com sua família do interior do Estado do Rio de Janeiro para a região da Chácara do Vintém, na Tijuca, onde Mano Elói fundaria, em 1934, a Escola de Samba Deixa Malhar. Para Rubens da Vila, "Mano Elói era simplesmente tudo, história, tudo".

Antes de fundar a Escola de Samba Deixa Malhar, porém, ele participou ativamente das rodas de samba no Morro da Favela, no Morro de Santo Antônio e nas áreas suburbanas da cidade. Nessa época, o samba era cultuado em locais secretos em virtude da repressão policial. Jota Efegê descreveu Mano Elói, como bamba na capoeira, no rabo de arraia e no samba raiado. Segundo o cronista, Mano Elói participou de uma luta de exibição com o grande capoeirista Ciriaco, no antigo pavilhão 9, na antiga Rua Larga, atual Marechal Floriano, próximo do Morro da Conceição, no Centro. Interessante frisar que, embora possa haver algum exagero na narrativa heróica sobre o sambista, não resta dúvida de que a capoeira, mistura de dança e arte marcial, está inscrita na história dos primeiros 
cordões e blocos carnavalescos. Tinhorão (1972) observa que, em 1870, eram as coreografias acrobáticas denominadas "caboclos" que abriam os caminhos dos ranchos organizados pelos baianos da região da Saúde, seguidas pelas Danças de Velho e pelos demais cordões: Rei dos Diabos, Pincês, Dr. Bruno, o Palhaço. Daí surgiram inúmeros passistas negros e mestiços que, em 1920, formaram a base do samba carioca.

Em 1925, o Jornal do Brasil recebeu uma homenagem dos carnavalescos da região suburbana de Engenheiro Leal. O anúncio (Em Engenheiro Leal, homenagem ao Jornal do Brasil) descreveu a programação de mais uma batalha de confete e lança-perfume no bairro, região de atuação do sambista Mano Elói. ${ }^{3}$ O patrocinador do evento, o Argentino Futebol F.C., chamou a atenção dos leitores mostrando que o evento contaria com a presença dos blocos Feltamina, Minha Nêga, Têteas, Você não pode, Elles te dão, Fellaberta, Minha Branca, entre outros. $\mathrm{O}$ anúncio também relacionou os promotores do evento: Francisco Gama (Lord Trouxa), Osmar Monteiro de Barros (Lord Só, Director), João Ribeiro (Lord Frajota), Honório Ferreira (Lord Sine) e Antônio (Lord Ban-ban-ban). E, para complementar a festa, os foliões do bairro de Engenheiro Leal anunciaram um samba "enredo" que seria defendido pela turma do Augusto (Lord Brincadeira):

Inteligente // Por Deus juro que não posso / Mais sofrer / Por tua causa mulher do meu / Bem quer / As tuas mágoas são minha desventura / Vou depor aos pés de Deus / Vou baixar a sepultura // II // Momo no Cattete, onde mora o / Presidente / Lá é Zona "ckike" também mora boa / Gente / Como não sou trouxa também / Posso me misturar / Vou bancando o inteligente até / A coisa melhorar // III // Por Deus juro, etc. etc. / Tomei o trem na central prá / Soltar na piedade / Vou parar em Dona Clara saber / Logo das novidades / Tomo o trem em D. Clara desen / barco em Piedade / Encontrei Mano Tavares, disse o / Samba é na cidade // IV // Estando com Mano Eloy / Com seu lindo terno Azul / Nos embarcamos no bonde de / Itapiru / E ao mesmo tempo encontro Mano / Chanju / Elle disse vou pro samba na / Casa da Dudu // V // Mana Dudu de bom parecer / Da brincadeira pra quem quizer / Ir lá ver / Damas e cavalleiros sempre tem / A escolher / Depois da contra-dansa temos / Damas ao "buffer" (JORNAL Do BRASIL, 25/1/1925, p. 12).

A batalha de confete de Engenheiro Leal foi realizada na Rua Francisco Valle. A origem do bairro está ligada à implantação da Estrada de Ferro Melhoramentos do Brasil, que se tornou uma linha auxiliar em 1892, momento em que foi construída a referida estação, no início do século XX, em homenagem a um fiscal 
da estação ferroviária. O anúncio não cita a autoria do samba, mas não resta dúvida de que sua abordagem se insere no processo de integração dos subúrbios.

A Presidência da República, em 1925, era ocupada por Arthur Bernardes, governo marcado por profunda crise política. Os carnavalescos de Engenheiro Leal destacaram com muito humor e pragmatismo a situação cotidiana: "Como não sou um trouxa posso me misturar", "vou bancando inteligente até a "coisa melhorar."

O samba ocupou importante espaço na cultura de massa nas primeiras décadas do século XX. Assim, a ideia de misturar pode ser vista como uma tática inteligente, sobretudo para as populações negras e mestiças ao explorar a ideia de "democracia racial". Segundo Gomes (1998), a ideia de democracia racial representou uma forma inteligente de atuação das classes populares. Dessa forma, antes do livro Casa Grande \& Senzala, cuja primeira edição foi em 1933, já havia intensa discussão sobre as relações entre raça e nação no Rio de Janeiro e São Paulo. A Companhia Negra de Revista destacou-se com a atuação de artistas negros: Pixinguinha, Bonfiglio de Oliveira, Sebastião Cirino e De Chocolat. A peça Tudo preto exerceu papel fundamental ao enfatizar questões como identidade nacional, mestiçagem, influências negras, racismo - questões que se tornaram centrais a partir do livro de Gilberto Freyre e do próprio modernismo. Na escolha dos nomes dos blocos, os carnavalescos ironizaram uma visão dicotômica das "raças", como, por exemplo, em "Minha Nêga", "Minha Branca".

Segundo o Jornal do Brasil, o samba denominado "Inteligente", foi cantado pelo Augusto (Lord Brincadeira). Nota-se no próprio nome do folião a definição do samba, pois, do ponto de vista dos bantos da região de Angola, o samba em sua essência se constitui como elemento de sociabilidade, como um jogo de alegria e tristeza, que joga com o corpo instituindo processo de sedução. O samba é um elemento de aproximação de pessoas e anexação de espaços, como o trem que encurta as distâncias, desfragmentando o território e semeando o terreiro na cidade, independentemente da cor e do lugar do indivíduo na sociedade. Segundo o historiador Joel Rufino (2004, p. 151), o samba pode ser definido como narrativa dos grupos negros que imigraram para cidade do Rio no início do século XX:

Ao dizer samba não se está falando, pois, somente de um tipo de música - a própria ideia de música, aliás, não é universal; música é um fato social total para além da "arte de combinar sons de maneira agradável" (Rousseau) ou mesmo "a ciência ou emprego de racionais do som segundo uma escala dita gama". A base material do samba são os grupos negros urbanos cariocas em interação (trocas 
e friçções) com outros, inclusive grupos rurais (Estado do Rio e Minas) recém-imigrados. Samba é veículo musical de sociabilidade trabalhos, festas, rituais, linguagem, hábitos - desses grupos. Há, pois, samba gênero musical - sambas, talvez fosse melhor dizer - e samba forma histórica de sociabilidade ou lugar social.

O compositor da Estação Primeira de Mangueira Carlos Cachaça (sılvA et al., 1980) observou que era da região de Engenheiro Leal que vinha a turma do Mano Elói para batucar no buraco quente. Assim a letra do samba "Inteligente" não ratifica apenas a memória do sambista da Mangueira, mas a própria memória social como um elemento capaz de construção de sujeitos. Os atos de lembrar e esquecer estão sempre se alternando, num jogo de relação de forças.

O samba "Inteligente" descreveu a indumentária do sambista Mano Elói, cujo terno era "lindo" na cor azul, e com isso realçou o prestígio do sambista. Em 1925, estavam no auge os concursos de samba e as rodas de samba, ligando o subúrbio com a cidade. Assim, provavelmente, a casa da Mana Dudu, na região do Catumbi, era uma linha de bonde que ligava a região ao Centro da cidade. E o verso que cita Mano Tavares, afirmando que o "samba é na cidade", aponta o destino dos sambistas, em direção à região do bairro do Estácio. Contexto histórico em que os blocos se transformaram em escolas de samba, como o famoso Deixa Falar, em 1929.

A casa da Mana Dudu também simboliza o espaço de acolhimento do samba na cidade. Espaço de sociabilidade que foi muito bem definido na figura mitológica de tia Ciata. A pesquisadora Helena Theodoro (2009, p. 235), ressaltando a contribuição feminina nesses espaços, descreve a relação do samba em sua coexistência com as manifestações de origem religiosas:

Samba é um fenômeno que só tem explicação na energia que vem das casas de omolokô, da tradição religiosa de base africana, como afirma o radialista Rubem Confete, tendo juntado o culto às almas, da gira de Preto Velho e caboclo e do culto aos orixás. Foi assim que nasceu a Portela, da energia de Seu Napoleão Nascimento, que era pai de Natal. No Estácio, foi a energia de Tancredo Silva, grande pai de santo de omolokô. Na Mangueira, Dona Maria de Fé foi estimulada por Elói Antero Dias para que criassem uma escola de samba. Antes de fundar o Império Serrano, o Sr. Elói fundou o Deixa MaIhar, no baixo Tijuca.

O texto destaca a atuação de Mano Elói, no Morro da Mangueira, incentivando a formação de uma escola de samba, aspecto que provavelmente antecedeu a fundação da Escola de Samba Deixa Malhar, em 1934. Nesse ano, o Diário Carioca (7/1/1934, p. 4) informou que Mano Elói assumiu a presidência da Escola 
de Samba União Parada de Lucas. Em seu currículo também consta a participação nas sociedades recreativas Filhos da Campina (DIÁRIO CARIOCA, 16.2.1936), Cordão de Velhos (JORNAL DA MANHÃ, 9.7.1949, p. 13) e Flor de Romã. Carlos Cachaça (SILVA, 1980, p. 28) lembrou que na época do Rancho Pérola do Egito, no Morro da Mangueira, Mano Elói cantou na casa de tia Fé um partido-alto de autoria coletiva, prática muito comum nos carnavais da festa da Penha:

Nessa época, o samba começava a aparecer em Mangueira, trazido quase sempre pelo "moleque" Elói - Elói Antero Dias. Ele morava na famosa estação de Dona Clara, reduto dos maiores valentes, macumbeiros e batuqueiros. Ele chegava aqui sempre acompanhado de Pedro Moleque, Pedro Lambança e outros. O terreiro preferido deles era o da Tia Fé. Elói era pai de santo respeitado. Nos terreiros tinha a festa do santo. Quando terminava, entrava o samba. A música que predominava em todos os lugares, aqui era de autoria de Elói e foi, por muito tempo, a coqueluche de vários carnavais e festejos da Penha.

Ao se analisar a trajetória do sambista, fica difícil não imaginar que diante da presença do Mano Elói no Morro da Mangueira, ele não tenha participado de um jogo da malha. Enquanto o futebol, no início do século $X X$, era atividade muito mais voltada para os jovens da elite carioca, o jogo da malha estava difundido em todo subúrbio e costumava reunir alguns capoeiras, malandros e muito batuque. A jongueira Nininha, do Morro da Mangueira, recordou que no morro existiu um Clube da Malha, que foi levado pelos portugueses. Havia muita música nesse espaço e, aliás, um músico chamado Bataleão tocava nesse clube. Ao notificar essa lembrança de Nininha, façamos dela um fio entre os clubes de malha e o samba. Seria esse o espaço em que Mano Elói se inspirou para nomear o bloco, rancho e finalmente Escola de Samba Deixa Malhar? Se o futebol gerou processos de sociabilidade que resultaram em muitas escolas de samba, quem sabe o jogo da malha nos tenha dado uma das primeiras? Acredito que sejam hipóteses plausíveis para reunir os fios dessas lembranças, das quais, às vezes, não há registros documentais.

A dinâmica da cultura negra na música e na dança assimilou-se ao universo do carnaval carioca unindo diferentes manifestações culturais. Nesse sentido, destaco a parceria entre Mano Elói, natural do Vale do Paraíba, interior do Estado do Rio de Janeiro, e do baiano Getulio Marinho, em 1934. Getulio Marinho, que foi também um dos maiores mestres-salas dos ranchos, tornou-se secretário da primeira Diretoria da União das Escolas de Samba. ${ }^{4}$

Falar a respeito dessas primeiras agremiações de samba nos coloca diante de trocas de experiências que nos conduzem ao tempo dos ranchos. Parte des- 
sa tradição teve origem nas práticas do baiano Hilário Jovino, que concebeu uma nova característica em relação à antiga estrutura religiosa advinda da experiência católica do ciclo natalino, denominada lapinha, que surgiu no Recôncavo Baiano. Assim, gradativamente, essa estrutura foi adaptada do natal, transferindo-se para o circuito do carnaval, condensando o sagrado e o profano, o que acabou dando formato definitivo às escolas de samba.

A amizade de Mano Elói com o compositor Getulio Marinho, sobrinho de Hilário Jovino, resultou no convite para que o sambista registrasse em discos os primeiros cânticos de umbanda no Brasil. Mano Elói era uma grande solista de pontos de macumba, pois era ogã no terreiro do babalaô Luis Cândido Jonas. 0 registro resultou em uma gravação que contou com a participação das filhas de santo Maria e Rosa. Dessa forma, em setembro de 1930, a Odeon lançou o disco 10.679, em que Elói canta no lado A o Ponto de Inhassã (Santa Bárbara) e no lado B o Ponto de Ogum (São Jorge). O fonograma foi muito bem recebido pelo mercado, e o Diário Carioca publicou a seguinte nota:

Odeon:"Macumba". Ponto de Inhassan e Ponto de Ogum - Eloy Anthero Dias e Getulio Marinho com o conjunto africano. Número 10.679. Nas extranhas cerimônias dessa perturbadora religião do elemento negro do nosso povo, na qual a base é uma mistura de crendices africana com superstições do catholicismo (...) É a gente que no "terreiro" se entrega aos numerosos detalhes do esquisito rito, com espírito agitado por uma espécie de allucinação coletiva, Aqui estão elles, ora melopéa do ponto de Inhassan, ora no soturno no ponto de Ogum. A odeon apresenta com este disco trabalho phonografico primoroso que constitue um dos maiores acontecimentos do anno corrente, por isso chamamos a attenção para chapa, tanto mais porque Ella é, surprehendente revelação que se não esquece ( CORREIO DA MANHÃ, 24/8/1930, p. 5).

Nesse contexto, o Brasil se inseriu no processo de valorização da cultura negra mundial. Foi o momento do sucesso da bailarina afro-americana Josephine Baker, em Paris, como estrela do espetáculo Revue Nègre no famoso teatro des Champs Élysées, no seu quadro danse sauvage. Tivemos também a trajetória dos Oitos batutas. O charleston, gênero dançante norte-americano, embalou o movimento dos corpos nas casas de danças da cidade do Rio. Para Gomes e Domingues (2013) isso tudo refletiu os "fluxos e refluxos dos paradigmas comportamentais que cruzaram Atlântico e aportaram no Brasil".

Mano Elói teve a oportunidade de registrar em fonogramas "Não vai no candomblé" no lado A do disco 10.719 e, no lado B, outro samba assinado por Getulio Marinho intitulado "Não quero teu amor" acompanhado pelo conjunto 
Africano. A atuação de Elói encerrou-se com dois jongos: "Galo Macuco" e "Liberdade dos Escravos" (10.736) (VASCONCELOS, 1985, p. 238).

Em 1936, o jornal A Rua resolveu lançar o concurso Cidadão Samba, organizado pelo cronista carnavalesco Luiz Nunes da Silva, mais conhecido como Enfiado. O matutino acolheu algumas tensões, sobretudo no meio dos sambistas, advindas pela forma como se processou a escolha do Cidadão Momo, o sambista Paulo da Portela. Para Cunha (2002) o carnaval deve ser analisado numa perspectiva que valorize sua diversidade, seus conflitos e contradições. Assim, a festa deve ser representada numa dimensão que enfatize um "campo de batalha", em que diferentes grupos buscam legitimidade para suas práticas. Dessa forma como era de esperar, três dias após o evento de homenagem ao Cidadão Momo, o Diário Carioca $(16 / 2 / 1936$, p. 5) recebeu, em sua redação, a visita de Elói Antero Dias:

O Cidadão Samba em visita ao Diário Carioca: Eloy Antero Dias, que por iniciativa de "A Rua" vem de ser eleito "Cidadão Samba" visitou o Diário Carioca. O Cidadão Samba que é um dos baluartes da "Escola de Samba" Deixa Malhar, se fazia acompanhar do presidente daquela escola Carlos Bastos, do Sr. Rubens Gomes da Prazer da Serrinha; Boa Ventura Ricardo Pereira, dos Unidos do Cavalcante e do "Chronista" carnavalesco Enfiado de "A Rua". Ontem mesmo o Cidadão Samba, "assignou" o primeiro decreto nomeando seus secretários oficiais o Sr. Severino Lins, elemento prestigioso da Escola de Samba prazer da Serrinha e do Chronista Luiz Nunes da Silva, Enfiado.

Na figura 1 registramos a presença de Mano Elói, ao centro, entre diretores da Escola de Samba Deixa Malhar, ao lado do jornalista Luiz Nunes da Silva, o Enfiado. A imagem provavelmente foi produzida com o objetivo de promover Mano Elói no concurso Cidadão Samba. A foto chama a atenção pela presença altiva e marcante de Mano Elói, cuja postura hierática denota um olhar desafiador para o público. É interessante notar na imagem que todos se colocam com expressão muito séria, dando um tom solene, além de bem alinhados. A presença do grupo na foto é uma forma de enfatizar legitimidade do primeiro cidadão samba. Ferreira (2004) destacou um modo de vestir mais ousado dos sambistas, com base na moda do malandro negro norte-americano, cujo destaque foi o cantor de jazz Cab Calloway - ombros acentuados, calças amplas, postura afirmativa e rebelde - e que foi incorporada nos trajes do malandro carioca.

A eleição do Cidadão Samba foi uma forma de ratificar a importância de um tipo de samba que se praticava na região da Tijuca. Foram as famosas batucadas da Deixa Malhar que chancelaram a articulação do primeiro Cidadão Samba 
carioca. O esquecimento da trajetória do cidadão samba não foi por acaso; tem a ver com métodos de produção do conhecimento e as tensões que orientam muitas narrativas sobre o samba.

A cidade do Rio também recebeu muitos negros que participaram da Guerra do Paraguai, e, enquanto aguardavam as indenizações, devidas pelo governo do Distrito Federal, muitos foram-se fixando, na medida do possível, nos diversos morros da cidade. Dessa forma, muitos valentes são resultado da combinação de expropriação de força de trabalho na guerra e autoestima proveniente da sobrevivência no conflito. Muitos encontram espaço na organização das primeiras escolas de samba. O uso da valentia, num mundo semiurbano, foi saída muito utilizada na resolução de contendas políticas. Sodré (2002) destacou a violência ritualística ligada a fatores místicos no sentido de expressar a força masculina. Para o filósofo Nietzsche, a violência se apresenta como tabu, posto que na cidade não há lugar para a "festa das pulsões", pois se busca, a todo o instante, o recalque do diferente em prol da homogeneidade. Assim, a cultura citadina forma os processos de coerção das pulsões, o que é traço próprio da modernização a serviço da ordem disciplinar e tem como intuito a esterilização das forma expressivas, sendo o corpo uma forma de linguagem. Dessa forma, o carnaval no tempo da Praça Onze de Junho é caracterizado como a pré-história do carnaval disciplinado, e a trajetória de Mano Elói é lembrada como sinal de um tempo não domesticado:

Num dos carnavais da década de 30, a Deixa Malhar foi campeã de um desfile realizado na Praça XI em virtude de Mano Eloy [ter] intimidado a comissão julgadora quando a escola fazia evolução em frente ao palanque destinado ao jurados. Tido como valente, Mano Eloy era homem respeitado na "beira do cais" (estiva) na roda de samba e nas gafieiras" (CORREIO DA MANHÃ, 12/1/1970, p. 7).

Mano Elói foi um mediador do mundo do samba que frequentou as batucadas da tia Ciata. Segundo Cabral (1996) o sambista foi fundamental para a concepção de negritude carioca. Fernandes (2001) enfatizou o lado autoritário do sambista na condução da União Geral das Escolas de Samba, enquanto Bissole (2012) ressaltou sua contribuição como um dos produtores do samba brasileiro, ao lado de nomes como Donga, Cartola, Mano Edgar, Mano Rubem (Rubens Barcelos), Ismael Silva, Baiaco, Carlos Cachaça, Wilson Batista, comparando, aliás, a capacidade de articulação de Mano Elói à figura enigmática da tia Ciata no processo de continuidade da cultura negro-brasileira, sobretudo no movimento das escolas de samba.

Mano Elói e Heitor dos Prazeres representaram as escolas de samba nas cerimônias oficiais do governo Vargas, ajudando a pavimentar o caminho das es- 


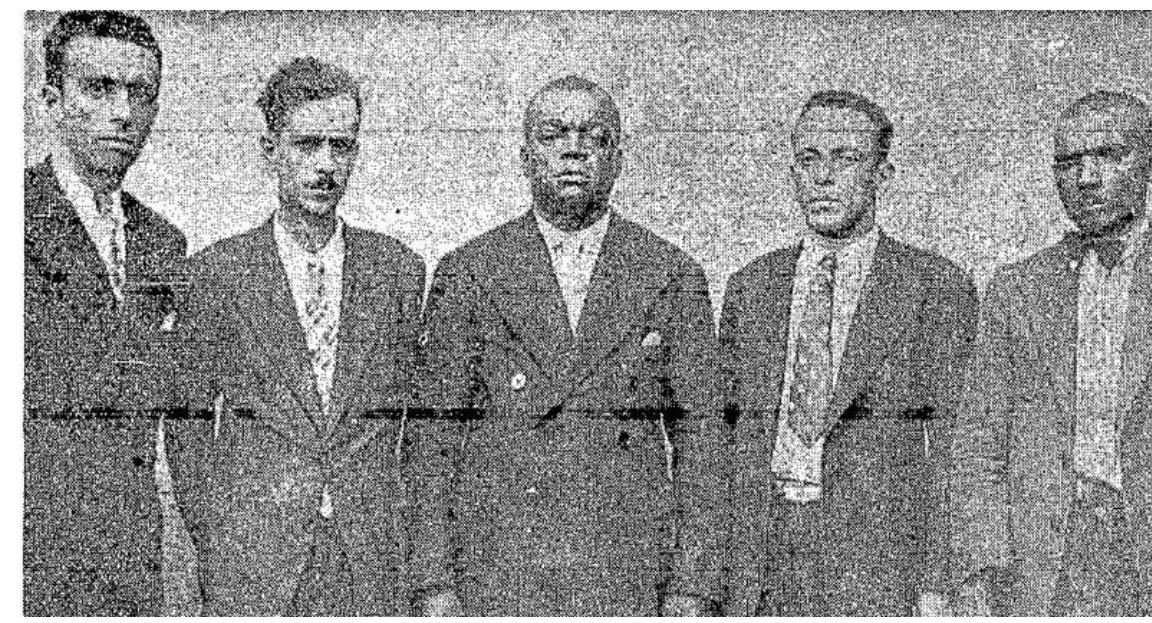

Figura 1: Mano Elói, no centro da fotografia tendo a sua direita o cronista "Enfiado" (Luiz Nunes da Silva), e os diretores da Escola de Samba Deixa Malhar (EFEGÊ, 1974)

colas de samba, antes mesmo da oficialização dos desfiles, em 1935. Segundo o Jornal do Brasil (28/3/1968, p. 17) a Escola de Samba Deixa Malhar foi fundada em 1934. Em 1935, o jornal A Manhã (28/9/1935, p. 6) publicou a relação dos nomes dos representantes da primeira Diretoria da agremiação, ${ }^{5}$ que tinha o sambista Carlos Bastos como presidente. Além das atividades voltadas para o carnaval, a associação carnavalesca também exercia as de clube esportivo, possuindo várias modalidades de esporte, como futebol e jogo da malha. Seu pavilhão era representado pela cores vermelho e branco.

Concluindo, registramos o anúncio publicado no Jornal do Brasil em 18/5/1934 (p. 18). É um dos primeiros comunicados da Deixa Malhar nos jornais e faz a menção a uma conhecida escola de samba da Chácara do Vintém. O texto de divulgação pode ser interpretado como estratégia de visibilidade, potencializando um evento no tradicional espaço do Fenianos, um dos clubes carnavalescos mais tradicionais da cidade e conhecido por sua posição republicana. Dessa forma, a ideia de bloco familiar destaca a estratégia desses primeiros grupos de escolas de samba na busca de aceitação social, mas de acordo com a nova conjuntura do país.

B.C Familiar Deixa Malhar: No próximo domingo. B.C Familiar "Deixa Malhar", conhecida "escola de samba" da "Chácara do Vintém", realiza uma grande festa nos salões do clube Fenianos, da Praça da Bandeira. São Cristovão 210.a festa terá inicio as 14: horas e terminará as 02 horas. As 18 horas será suspensa a festa para o "grude" que constara de um valente "rabo de boi com agrião". 


\section{NOTAS}

1 Um retrato da favela da Barreira do Vasco. Inquérito da Fundação Leão XIII. Rio de Janeiro, 25/05/1948 (CORREIO DA MANHÃ, 25/5/1948, p.1).

2 Entrevista do compositor Rubens da Vila (Rubens Batista Vianna) em 2010.

3 Mano Elói $(20 / 2 / 1971$, p. 2) afirmou ter participado dos ensaios na Portela, quando ainda era bloco, indo depois para a Escola de Samba Deixa Malhar: "Meu entusiasmo com carnaval começou ainda nos ranchos. Em 1920 comecei com o negócio de escola de samba. Era um bloquinho, a Portela. Depois as coisas foram melhorando, pois o povo passou a gostar de samba e todo mundo se empolgou."

4 Está assim organizada a directoria da União das Escolas de samba, com sede á Rua Itapagipe no 393: Presidente, Flavio Paula Costa (Deixa Malhar); vice, Saturnino Gonçalves (Estação Primeira);10 secretário, Jorge de Oliveira (Depois eu digo); 2으 secretário, Getulio Marinho; 1o procurador Pedro Barcellos (Príncipe, da floresta);2 dito Luiz Gonzaga (Paraíso do Grotão); 3 dito, Armando (A de Ramos); 1ㅇ thesoureiro, Paulo de Oliveira (Vai como Pode); 2 dito, José C.Belisario (Prazer da Serrinha) (A BATALHA, 10/1/1934, p. 5).

5 Presidente: Carlos Bastos; vice-presidente: Armando da Silva; 1 o secretário, Eugenio Athanasio; 2으 secretário José Espírito Santo; 10 tesoureiro, Antonio Ferreira Alves 20 thesoureiro, José Ferreira Alves, 10 procurador, Antonio Pinheiro 2 - procurador, Ulysses Luiz Barbosa. Conselho Fiscal: Benedido Mariano de Souza, Francisco Gomes, Amaro Nogueira, Waldemar dos Santos e Alcydes Pinheiro. Um programa "monstro" - Outros informes sobre a parada do samba (A MANHÃ, 28/9/1935, p. 6).

\section{REFERÊNCIAS BIBLIOGRÁFICAS}

BISSOLE, Magno. Identidade nacional: das origens à era Vargas. São Paulo: Unesp, 2012.

CABRAL, Sérgio. As escolas de samba do Rio de Janeiro. Rio de Janeiro: Lumiar Editora, 1996.

CUNHA, Maria Clementina Pereira (Org.). Vários Zés, um sobrenome: as muitas faces do senhor Pereira no carnaval carioca da virada do século. In: Carnavais e outras $f(r)$ estas: ensaios de história social da cultura. Campinas: Editora da Unicamp/cecult. 2002.

EFEGÊ, Jota. O saudoso Mano Elói. O Globo, Rio de Janeiro, 27/2/1974.

FERNANDES, Nelson da Nóbrega. Escolas de samba: sujeitos celebrantes e objetos celebrados. Rio de Janeiro: Arquivo Geral da Cidade do Rio de Janeiro, 2001.

FERREIRA, Felipe. $O$ livro de ouro do carnaval brasileiro. Rio de Janeiro: Ediouro, 2004. 
GOMES, Tiago de Melo. Lenço no pescoço: o malandro no teatro de revista e na música popular. "Nacional, popular e Cultura de Massas nos anos de 1920". Dissertação (Mestrado em história), IFCH da Universidade de Campinas, Campinas, 1998.

GOMES, Flávio dos Santos; DOMINGUES, Petrônio. Da nitidez e invisibilidade: o legado do pós-emancipação no Brasil. Belo Horizonte: Fino Traço, 2013.

MANO ELÓl. Estou doente, mas não deixei de ser carnavalesco. Jornal do Brasil, Rio de Janeiro, 20/2/1971, p. 2.

RUFINO, Joel dos Santos. Como podem os intelectuais trabalhar para os pobres. São Paulo: Global, 2004.

SILVA, Marília T. B.; CACHAÇA, Carlos; OLIVEIRA FILHO, Arthur L. Fala Mangueira. Rio de Janeiro: Livraria José Olympio Editora, 1980.

SODRÉ, Muniz. Mestre Bimba: corpo e mandinga. Rio de Janeiro: Manati, 2002.

THEODORO, Helena. Guerreiras do samba. Textos escolhidos de cultura e arte populares, Rio de Janeiro, v. 6, n. 1, 2009.

TINHORÃO, José Ramos. Música popular de índios negros e mestiços. Petrópolis: Vozes, 1972.

VASCONCELOS, Ary. A nova música da República Velha. Rio de Janeiro: Edição do autor, 1985

Sormani da Silva é graduado em história e especialista em educação pela Universidade Federal Fluminense, e mestrando no Programa de Relações Étnicoraciais do Cefet/RJ.

Recebido em: 16/09/2015

Aceito em: 18/10/2015 
